\title{
Synthesis, Properties and Biological Effectiveness of Iron Oxide Nanoparticles Via Calcinations Method
}

\author{
MAGED S. AL-FAKEH \\ Department of Chemistry, Faculty of Science, Qassim University, Qassim, Saudi Arabia. \\ ${ }^{*}$ Corresponding author E-mail: m.alfakeh@qu.edu.sa, alfakehmaged@yahoo.com
}

http://dx.doi.org/10.13005/ojc/360123

(Received: December 23, 2019; Accepted: January 28, 2020)

\begin{abstract}
In this study, an iron oxide nanoparticles (IONPs) was carried out via a calcinations method for a coordination polymers of iron derived from terephthalate and 2-aminothiazole. The iron oxide nanoparticles were described by FT-IR, XRD, transmission electron microscopy(T.E.M) and scanning electron microscopy (S.E.M). The thermodynamic and kinetic variables $\Delta \mathrm{H}^{*}, \Delta \mathrm{S}^{*}$ and $\Delta \mathrm{G}^{*}$ for the iron complex is calculated. The optical properties were investigated by UV-Vis and fluorescence techniques. From SEM and TEM observations, the morphology shape and size of the iron oxide nanoparticles is estimated to be significantly smaller than $32 \mathrm{~nm}$. The biological effectiveness of the IO NPs was tested successfully against some fungal and bacterial species.
\end{abstract}

Keywords: (IONPS) Iron Oxide Nanoparticles, XRD, SEM and TEM microscopy.

\section{INTRODUCTION}

Iron oxide nanoparticles (IONPs) are the inorganic compound, non-toxicity and can also easily be prepared in the laboratory. The existence of amorphous iron oxide $\left(\mathrm{Fe}_{2} \mathrm{O}_{3}\right)$ and four polymorphs alpha, beta, gamma and epsilon is well established. IONPs exhibit high saturation magnetization, biosensing, superparamagnetic properties, drugdelivery, leading to their biomedical applications such as anti-microbial (anti-bacterial, anti-fungal, magnetic sensing probes for in vitro diagnostics and tumor targeting..$^{1-6}$ In addition to this, they show interesting find applications in magnetic data storage..$^{7-12}$ In (NPs) nanoparticles, the surface zone to volume ratio significantly increased. This authorizes a considerably higher binding capacity of nanoparticles in solutions. The magnetic of nanoparticles, with sizes between 2 and $40 \mathrm{~nm}$ show superparamagnetism also they can be magnetized by an external magnetic exporter. The $\alpha-\mathrm{Fe}_{2} \mathrm{O}_{3}$ is a canted antiferromagnetic material. This advantage provides additional constancy for magnetic NPs in solutions. ${ }^{13,14}$ For the preparation of spherical iron oxide nanoparticles with some minor modifications, but completely different from Chen et al., ${ }^{15}$. In this article, we prepared and characterized a new compound obtained by the bridging, terephthalate, 2-aminothiazole and iron. The resulting complex was applied a precursor for preparation of nanoparticles of iron oxide.

This is an Open Access article licensed under a Creative Commons license: Attribution 4.0 International (CC- BY). Published by Oriental Scientific Publishing Company @ 2018 


\section{EXPERIMENTAL}

\section{Physical Measurements and Materials}

The terephthalate, 2-aminothiazole ligands and iron chloride used were commercially available and be given without further purification. The physical measurements in the same in this article. ${ }^{16}$

\section{Synthesis of $\left\{[\mathrm{Fe}(T P A)(A Z) C l] . \mathrm{H}_{2} \mathrm{O}\right\}_{n}$}

Preparation of the mixed ligand compound of terephthalate and 2-aminothiazole with $\mathrm{Fe}$ (III) as follows: To an EtOH solution $20 \mathrm{~mL}$ of iron(III) chloride ( $0.78 \mathrm{~g}, 4.8 \mathrm{mmole})$ a solution of terephthalate ( $0.8 \mathrm{~g}$ TPA ligand in $25 \mathrm{~mL} 0.1 \mathrm{M}$ sodium hydroxide, $4.8 \mathrm{mmol}$ ) was added dropwise, and with stirring, then 2-aminothiazole (AZ) solution $(0.48 \mathrm{~g}$ in $15 \mathrm{~mL} \mathrm{EtOH}$, $4.8 \mathrm{mmol}$ ) was added to the mixture. The mixture was refluxed and then cooled. Brown formed separated, which was filtered and washed with ethanol. Anal. Calc. for M.F; $\mathrm{C}_{11} \mathrm{H}_{10} \mathrm{~N}_{2} \mathrm{SFeClO}_{5}$ : C, 35.33; H, 2.69; N, 7.49; S, 8.58. Found: C, 36.02; H, 2.87; N, 7.92; S, 8.76. FtIR data: $v$ OH 3329 (s), v C=N 1614 (s), v C-N 818 (s), v M-O 582 ( m ), v M-N $418(\mathrm{~m}) \mathrm{cm}^{-1}$, m. p. $246^{\circ} \mathrm{C}$ and $\Lambda \mathrm{m} \mathrm{Scm}{ }^{2} \mathrm{~mol}^{-1} 47$.

\section{Formation of Iron Oxide Nanoparticles (IONPs)}

Via calcining methods the synthesized complex in air at $550^{\circ} \mathrm{C}$ with a calcination time of 180 min afforded (IO NPs) iron oxide nanoparticles.

\section{RESULTS AND DISCUSSION}

\section{Fourier Transform Infrared Spectroscopy (FT-IR)}

In the spectrum, as shown below in Fig. 1, displays a band at $582 \mathrm{~cm}^{-1}$ distinguishing for the iron-oxygen bond vibration in the crystal lattice of 10 nanoparticles ${ }^{17}$. Additionally, terephthalate is demonstrated by the appearance of a sharp band with a shoulder in the region 1356 and $1538 \mathrm{~cm}^{-1}$ which indicates symmetric and asymmetric stretching vibration of the $\mathrm{COOH}$ groups of the TPA arranged to the iron center. The bands in the area of 1715-1680 $\mathrm{cm}^{-1}$ regularly of protonated $\mathrm{COOH}$ groups of TPA were not observed ${ }^{18}$. It is appeared that the CSC band of AZ ligand appearing at $740 \mathrm{~cm}^{-1}$ is nearly unchanged, in the particular iron compound, shown that the thiazol-S is not implicated in the bonding. The stretching vibration of $v(\mathrm{C}=\mathrm{N})$ of thiazole ligand for the complex 1 undergoes no shift comparing to assigned to $\mathrm{v}(\mathrm{C}=\mathrm{N})$ of the 2-aminothiazole $(\mathrm{AZ})$ $\left(1614 \mathrm{~cm}^{-1}\right)^{19-21}$.

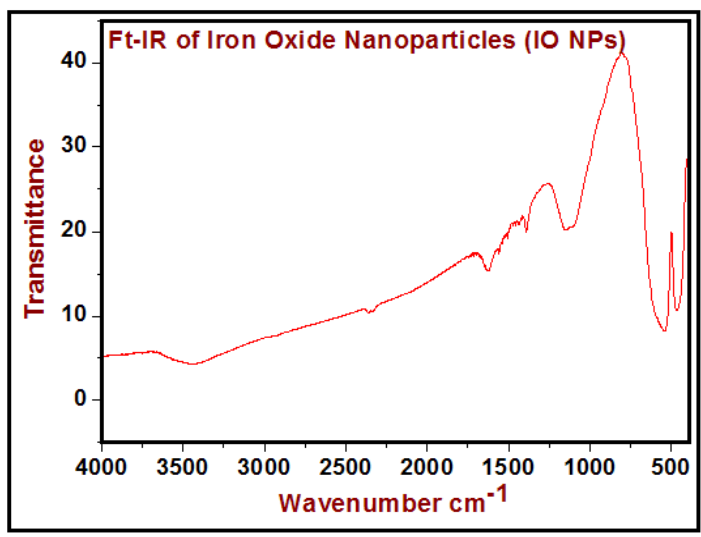

Fig. 1. FT-IR of iron oxide nanoparticles (IONPs)

\section{Spectral Analysis}

The UV-spectra of the mixed ligand compound and iron oxide nanoparticles are on record in dimethyl sulphuxide. The spectrum of iron complex shown two special bands at 36,836 and $26,246 \mathrm{~cm}^{-1}$, which are ascribe to $\pi \rightarrow \pi^{*}$ and $\mathrm{n} \rightarrow \pi^{\star}$ transitions within the TPA and AZ organic ligands, respectively. It is apparent that the spectra exhibit a band absorption edge at $354 \mathrm{~nm}$.

\section{Magnetic Moments}

In the Vis-spectra, there was particularity band refered to the $d-d$ transitions in the iron complex typical of octahedral structure (Fig. 2). The $d-d$ band at $19,178 \mathrm{~cm}^{-1}$ was observed for iron complex. The magnetic moment value for the iron compound was 2.82 B.M typical for octahedral complex ${ }^{22}$.

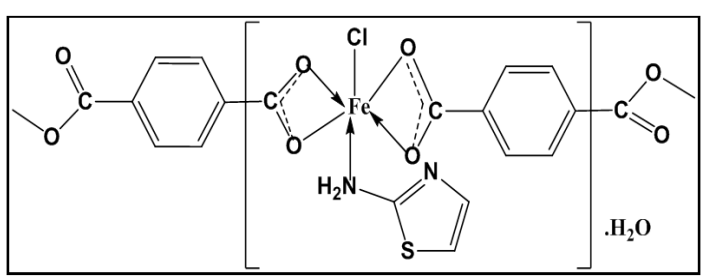

Fig. 2. Structure of $\left\{[\mathrm{Fe}(T P A)(A Z) C l] \cdot \mathrm{H}_{2} \mathrm{O}\right\}_{n}$

\section{Thermal Analysis}

The thermal analysis of the $\{[\mathrm{Fe}(\mathrm{TPA})(\mathrm{AZ})$ $\left.\mathrm{Cl}] . \mathrm{H}_{2} \mathrm{O}\right\}$ n coordination polymer has been inspected from ambient temperature to $750^{\circ} \mathrm{C}$. Thermogram of iron complex displays four decomposition stages (Fig. 3 ), stages at 26-149, 150-277, 278-453 and $454-750^{\circ} \mathrm{C}$. The $1^{\text {st }}$ and $2^{\text {nd }}$ steps correspond to the detachment of the crystalline water molecules (calc. $4.82 \%$, found $4.70 \%$ ). The DTG curve shows this stage in $86^{\circ} \mathrm{C}$ and endothermic peaks at $88^{\circ} \mathrm{C}$ 
in the differential thermal analysis (DTA) trace. The $3^{\text {rd }}$ and $4^{\text {th }}$ stages correspond decomposition of the rest of the ligands derivative thermogravimetry peaks at 238,356 and $456^{\circ} \mathrm{C}$ with three exothermic peak in the differential thermal analysis trace at 240, 358 and $458^{\circ} \mathrm{C}$. The ultimate product at $550^{\circ} \mathrm{C}$ is consistent with the formation of iron oxide nanoparticles (IONPS).

\section{Kinetic Studies}

The non-isothermal kinetic studies of the coordination polymer was carried out, stratify the coats-redfern ${ }^{23}$ method. The thermodynamic and kinetic variables for the iron complex is calculated for the $3^{\text {rd }}$ stage. The $3^{\text {rd }}$ stage shows a non overlapping stage with a derivative thermogravimetry and differential thermal analysis maxima. The negative $\Delta S^{*}$ value for the decomposition of the iron coordination polymer propose that the activated compound is more ordered than the organic ligands and iron chloride (reactants $)^{24}$. The more ordered nature may be, due to the polarization of bonds ${ }^{25}$ which may be happen through charge transfer (CT) electronic transition. The Positive value of free energy manifest that the decomposition reaction is not spontaneous.

Table 1:Thermodynamic and Kinetic variables for the thermal decomposition of the iron coordination polymer

\begin{tabular}{|c|c|c|c|c|c|c|c|}
\hline \multirow[t]{2}{*}{ Step } & \multicolumn{4}{|c|}{ Coats-Redfern equation } & \multirow[t]{2}{*}{$\Delta S^{*}$} & \multirow[t]{2}{*}{$\Delta \mathrm{H}^{*}$} & \multirow[t]{2}{*}{$\Delta G^{*}$} \\
\hline & $r$ & $\mathrm{n}$ & E & Z & & & \\
\hline \multirow{6}{*}{$3^{\text {rd }}$} & 0.9991 & 0.00 & 32.80 & $6.63 \times 10^{2}$ & -190.9 & 26.6 & 167.5 \\
\hline & 1.0000 & 0.33 & 51.82 & $10.44 \times 10^{2}$ & -187.2 & 45.6 & 183.9 \\
\hline & 0.9996 & 0.5 & 64.18 & $12.90 \times 10^{2}$ & -185.6 & 58 & 195 \\
\hline & 0.9991 & 0.66 & 77.97 & $15.64 \times 10^{2}$ & -184.1 & 71.8 & 207.6 \\
\hline & 0.9969 & 1.00 & 112.21 & $22.61 \times 10^{2}$ & -181.1 & 106.1 & 239.7 \\
\hline & 0.9919 & 2.00 & 121.01 & $48.39 \times 10^{2}$ & -175.0 & 114.8 & 244.0 \\
\hline
\end{tabular}

$\Delta \mathrm{G}^{*}, \Delta \mathrm{H}^{*}$, are in Kilo J. $\mathrm{mol}^{-1}, \Delta \mathrm{S}^{*}$ in Kilo J. $\mathrm{mol}^{-1} \mathrm{~K}^{-1}$ and $\mathrm{E}$ in Kilo J. $\mathrm{mol}^{-1}$

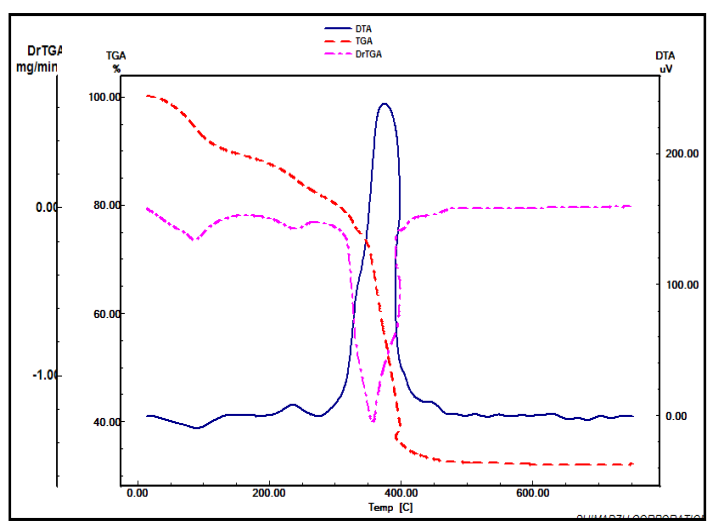

Fig. 3. Derivative thermogravimetry and differential thermal analysis of the iron complex
XRD of iron compound and iron oxide nanoparticles (IONPs)

The XRD patterns were recorded for the $\mathrm{Fe}$ (III) complex and $\mathrm{Fe}_{2} \mathrm{O}_{3}$ nanoparticles (Table 2). The diffraction patterns suggest that the iron complex and $\mathrm{Fe}_{2} \mathrm{O}_{3}$ nanoparticles are crystalline, also the crystal lattice variables were registered with the aid of the TREOR program. XRD of compound iron oxide nanoparticles is shown in Fig. 4, Scherrer's equation was used to estimate the particle size of the iron complex and iron oxide.

$(\mathrm{D}=\mathrm{K} \lambda / \beta \cos \theta)$

Where, $D$ is the mean size of the ordered (crystalline) domains, $\lambda$ is the $X$-ray wavelength typically $1.54 \AA$, $K$ is the shape factor, $\beta$ is the line broadening at half the maximum intensity in radians and $\theta$ is Bragg angle.

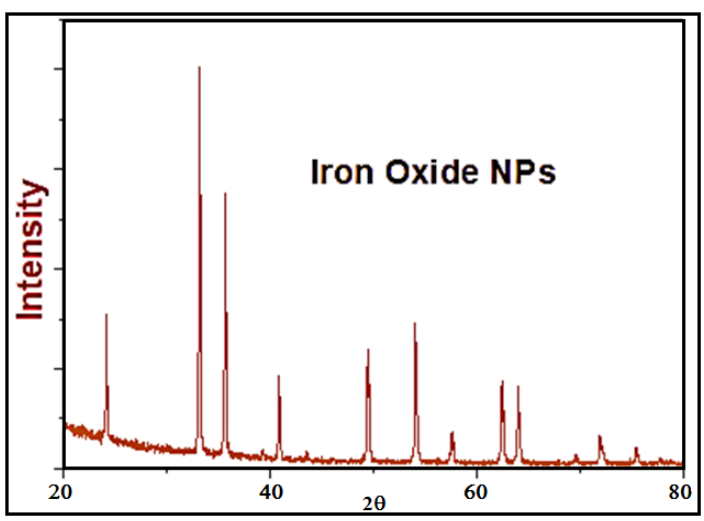

Fig. 4. XRD of iron oxide nanoparticles (IONPs)

Table 2: XRD crystal data of the iron complex and iron oxide

\begin{tabular}{ccc}
\hline Parameters & $\mathrm{Fe}(\mathrm{III})$ complex & Iron oxide \\
\hline Empirical formula & $\mathrm{C}_{11} \mathrm{H}_{10} \mathrm{~N}_{2} \mathrm{SFeClO}_{5}$ & $\mathrm{Fe}_{2} \mathrm{O}_{3}$ \\
Formula weight & 373.55 & 159.65 \\
Particle size $(\mathrm{nm})$ & 48 & 32 \\
Volume of unit cell $(\AA 3)$ & 654.31 & 301.72 \\
Crystal system & Triclinic & Hexagonal \\
$\alpha\left(^{\circ}\right)$ & 110.16 & 90 \\
$\beta\left(^{\circ}\right)$ & 59.95 & 90 \\
$\gamma\left({ }^{\circ}\right)$ & 101.29 & 120 \\
$\mathrm{a}(\AA)$ & 7.06 & 5.034 \\
$\mathrm{~b}(\AA)$ & 8.96 & 5.034 \\
$\mathrm{c}(\AA)$ & 12.7 & 13.745 \\
\hline
\end{tabular}

\section{Electron Microscopy (SEM and TEM)}

The transmission electron and scanning electron micrographs of $\mathrm{Fe}_{2} \mathrm{O}_{3}$ nano-particles 
(IONPs) are specified in Fig. 5-6. The highly crystalline nature of nanoparticles can be shown from transmission electron microscopy images and electron diffraction photos given in Figure 6.

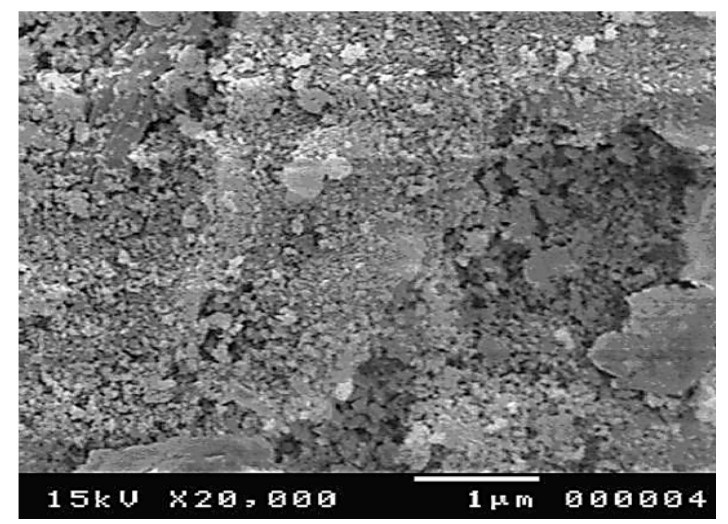

Fig. 5. S. E. M of iron oxide nanoparticles (IONPs)

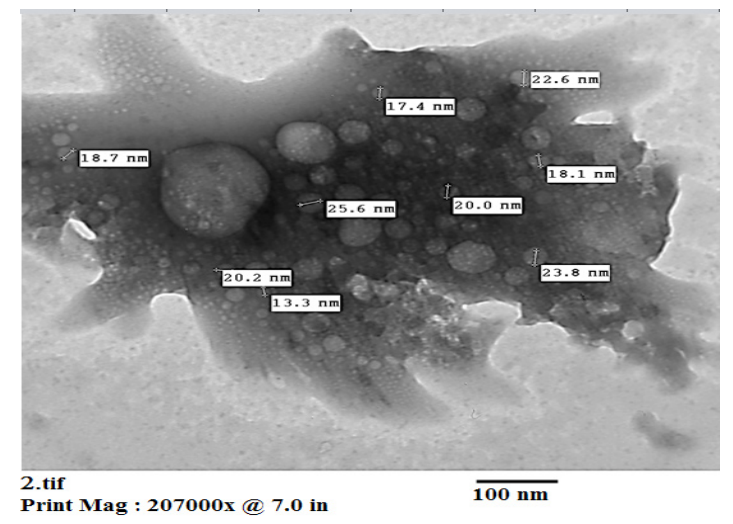

Fig. 6. T. E. M of iron oxide nanoparticles (IONPs)

\section{Antimicrobial Activity}

The antimicrobial effectiveness of the iron oxide nanoparticles (IONPs) was inspected against some bacterial and fungal strains ${ }^{21}$. In resulting the antimicrobial effectiveness of the (IONPs) was more than, one examination organism bacteria or fungi to increase the opportunity of discovering the antibiotic principles used in the tested materials, Fig. (7) show the antimicrobial effect for the (IONPs).

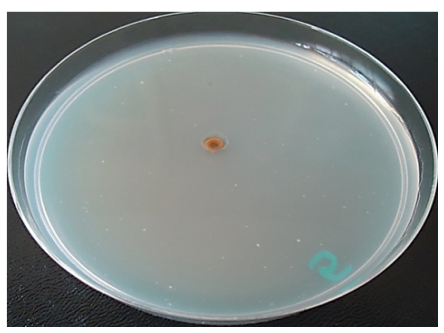

Fig. 7. Microbiological screening of the iron oxide against Staphylococcus aureus Gram-positive

\section{CONCLUSION}

In this study, we have presented in detail a simplified calcinations method for the formation of high quality magnetic $\alpha-\mathrm{Fe}_{2} \mathrm{O}_{3}$ nanoparticles (IONPs) also named hematite. Results of XRD sample display that all peaks, can be well recorded to the phase of hematite. T.E.M and S.E.M micrographs display that there are many micropores through the nanocrystals for the samples calcined at $550^{\circ} \mathrm{C}$ for 180 minute. The particle size of the IONPs in range 13-32nm.

\section{ACKNOWLEDGMENT}

We are grateful for AUMC (Assiut University Mycological Center) in Egypt for supporting this work by doing the antibacterial effectiveness of iron oxide (IONPs) was tested against Gram-negative -ve and Gram-positive +ve bacteria.

\section{Conflicts of Interest}

The authors declare no conflict of interest.

\section{REFERENCES}

1. Laurent, S; Forge, D; Port, M. Chemical Reviews., 2008, 108(6), 2064-2110.

2. Jia, Y; Yuan, M; Yuan, H. International Journal of Nanomedicine., 2012, 7, 1697-1708.

3. Park, J; Kadasala, N. R; Abouelmagd, S. A. Biomaterials., 2016, 101, 285-295.

4. Sun, Z; Worden, M; Thliveris, J. A. Nanomedicine: Nanotechnology, Biology and Medicine., 2016, 12(7), 1775-1784.

5. Atta, A. H; El-Ghamry, M. A; Hamzaoui, A; Refat, M. S. Journal of Molecular Structure.,
2015, 1086, 246-254.

6. Gupta, A. K; Gupta, M. Biomaterials., 2005, 26(18), 3995-4021.

7. Karimzadeh, I; Dizaji, H. R; Aghazadeh, M. Journal of Magnetism and Magnetic Materials., 2016, 416, 81-88.

8. Augustin, E; Czubek, B; Nowicka, A. M; Kowalczyk, A; Stojek, Z; Mazerska, Z. Toxicology in vitro., 2016, 33, 45-53.

9. Yin, P.T; Shah, S; Pasquale, N. J; Garbuzenko, O. B; Minko, T; Lee, K.-B. Biomaterials., 2016, 81, 46-57. 
10. Mallick, N; Anwar, M.; Asfer, M. Carbohydrate Polymers., 2016, 151, 546-556.

11. Jain, T. K; Foy, S. P; Erokwu, B; Dimitrijevic, S; Flask, C. A; Labhasetwar, V. Biomaterials., 2009, 30(35), 6748-6756.

12. Soares, P.I.P; Laia, C. A. T; Carvalho, A. Applied Surface Science., 2016, 383, 240-247.

13. Vu-Quang, H; Yoo, M.-K; Jeong, H.-J. ActaBiomaterialia., 2011, 7(11), 3935-3945.

14. Li, H; Yan, K; Shang, Y. ActaBiomaterialia., 2015, 15, 117-126.

15. Chen, C.J; Chiang, R.K; Lai, H.Y; Lin, C.R. J. Phys. Chem. C., 2010, 114, 4258.

16. Maged S. Al-Fakeh, Fahad M. Alminderej, International Journal of ChemTech Research., 2018, 11(05), 442-449.

17. Yang, K; Peng, H; Wen, Y; Li, N. Appl. Surf.
Sci., 2010, 256, 3093.

18. Biemmi, E; Biemmi, T; Stock, N. Solid State Sciences., 2006, 8, 363.

19. Maurya, R. C; Verma, R; Singh, H. Synth. React. in Inorg. and Metal-Org. Chem., 2003, 33, 1063.

20. Rakha, T. H. Synth. React. Inorg. Met.-Org. Chem., 2000, 30, 205.

21. Maged S. Al-Fakeh. Journal of Chemical and Pharmaceutical Research., 2018, 10(2), 77-83.

22. Westerheide, L; Muller, F. K; Than, R; Krebs, B. J. Dietrich and Schindler, Inorg. Chem., 2001, 40, 1951.

23. Coats, A; Redfern, J. Nature., 1964, 20, 68.

24. Yusuff, K. M; Karthikeyan, A. R; Thermochim. Acta., 1999, 207, 193-199.

25. Emam, M. E; Kanawy, M; Hafe, M. H; J. Therm. Anal. Calorim., 2001, 63, 75-83. 